\title{
Basic Study on Development of System to Determine Machining Conditions for Minimizing Energy Consumed in Machine Tool
}

\author{
Yuki ARAKAWA ${ }^{1}$ and Hideki AOYAMA ${ }^{2}$ \\ Dept. of System Design Engineering, Keio University \\ 3-14-1 Hiyoshi, Kohoku-ku, Yokohama, 223-8522 Japan \\ Tel: 045-566-1722, Fax: 045-566-1720 \\ ${ }^{1}$ Master's student, E-mail: arayuu0906@ina.sd.keio.ac.jp \\ ${ }^{2}$ Professor, E-mail: haoyama@sd.keio.ac.jp
}

\begin{abstract}
:
The objective of this study is to develop a system to determine optimal machining conditions for minimizing energy consumed in machine tools. To realize this objective, we developed a module calculating the cutting energy and energy consumed in each unit comprising a machine tool, and applied it in experiments. The cutting energy was calculated using cutting force, torque of cutting force, and cutting power for square end milling and ball end milling. The energy consumed by each unit of the machine tool was also estimated through experiments based on real machine tools.
\end{abstract}

Keywords: CAM, End mill cutting, Cutting force, Cutting energy, Machine Tool, Minimizing energy

\section{Introduction}

When using CAM, machining conditions need to be provided by acquiring from database or by direct input by the operator. It is difficult for inexperienced operators to set appropriate machining conditions using general data bases, which often results in the need for skilled operators to modify the machining conditions based on their experience and intuition at the manufacturing site.

In recent years, environmental problems are becoming an increasingly serious issue throughout the world, and as a result, trends in the manufacturing industry are shifting away from "high-volume manufacturing and heavy consumption" to "eco-friendly". At plants, importance is placed more on consideration for the environment than achieving high accuracy. Amidst such efforts, "switch to specifications for energy saving" is also being considered. .

Under these circumstances, the objective of this study was to develop a system to determine optimal machining conditions for minimizing energy consumed in machine tools.

To develop this system, cutting force, torque of cutting force, cutting power, and cutting energy were calculated. A machining simulator using Z-map model was also developed to calculate the cutting force. In addition, energy consumed inside the machine tool other than cutting energy was estimated by experiments, the total energy consumed in the machine tool was calculated, and the machining conditions for minimizing this were determined.

\section{Machine Tool Energy Consumption Calculation System}

In this study, the energy consumed in a machine tool consists of both the cutting energy consumed on the cutting tool face in cutting work and the energy consumed by each unit of the machine tool.

In this study, the end milling tools such as square end milling and ball end milling was selected as the cutting tool, and the cutting energy used by the end milling tool was calculated for the two types of milling. In order to calculate the cutting energy, cutting force needs to be calculated, and in order to calculate this cutting force, the two parameters--cutting area and specific cutting force---are required. A machining simulator using Z-map model was therefore developed to calculate the cutting area $^{[1]}$

The energy consumed by each unit of the machine tool was estimated for a real machine tool; the V33 from MAKINO MILLING MACHINE CO., LTD (Japan, Tokyo). Electric power measurement experiments were conducted on each unit of the machine tool, and the measured power was modeled for each unit. The total energy consumed in the machine tool was then calculated by summing up all the measured power, and a module which can calculate all these powers simultaneously was developed.

\section{Cutting Energy Calculation Flow}

The following describes the flow of calculating the cutting energy consumed on the cutting tool face during the cutting process.

First, the cutting force generated at the interference areas between the cutting tool and workpiece is calculated. Next, the cutting power is calculated from the torque of the cutting force, and finally, the cutting energy is calculated using the cutting power. The calculation method is described specifically below. 


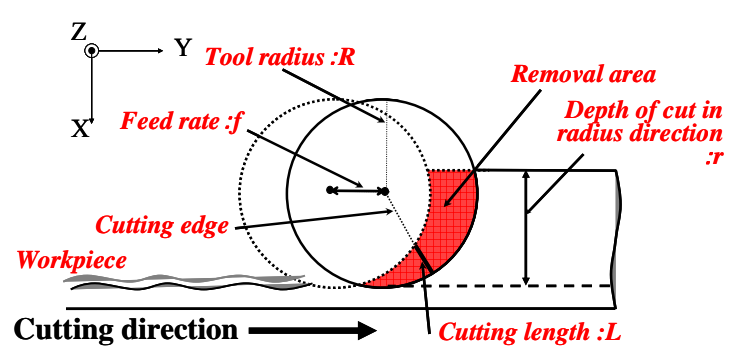

Fig.1 Relation between tool and workpiece at a certain time



Fig.2 Definition of cutting area in square end milling

\subsection{Cutting Force Calculation Method}

To calculate the cutting force, the cutting area needs to be calculated from the geometric shape of the interference between the cutting tool and workpiece in the cutting process.

Five parameters, namely tool radius " $R$ ", rake angle of cutting tool " $\varphi$ ", feed rate " $\mathrm{f}$ ", depth of cut in the $\mathrm{X}$ and $\mathrm{Y}$ directions " $r$ ", and depth of cut in the $\mathrm{Z}$ direction " $\mathrm{h}$ " must be determined to calculate the cutting area in square end milling, and from this cutting area, the cutting force can be calculated. Amongst these five parameters, tool radius " $R$ ", rake angle of the cutting tool " $\varphi$ ", and feed rate "f" are values given beforehand, while the depth of cut in the $\mathrm{X}$ and $\mathrm{Y}$ directions " $\mathrm{r}$ ", and the depth of cut in the $\mathrm{Z}$ direction " $h$ " are acquired from the processing simulator using the Z-map model.

Fig. 1 shows the relation of the interference between the cutting tool and workpiece at a certain time (the removed part in one cutting revolution). In this figure, the cutting length of the interference between the removed part and the cutting tool edge " $L$ " is required to calculate the cutting area. Using the tool radius " $\mathrm{R}$ ", the feed rate "f" and depth of cut in the $\mathrm{X}$ and $\mathrm{Y}$ directions " $\mathrm{r}$ ", the cutting length was calculated for each tool rotation angle that is the angle at which the cutting tool rotates around the tool center. The shaded area (cutting area " $\mathrm{S}$ ") in Fig.2 (area in which intersection points a-b-c-d are connected by straight lines) is calculated for each tool rotation angle using the cutting length " $L$ ", rake angle of the cutting tool " $\varphi$ ", and depth of cut in the $\mathrm{Z}$ direction " $h$ ". This shows that the cutting area in square end milling can be calculated using the five parameters.

In ball end milling as well as square end milling, the five parameters are also needed to calculate the cutting area. The cutting area is calculated by approximating the

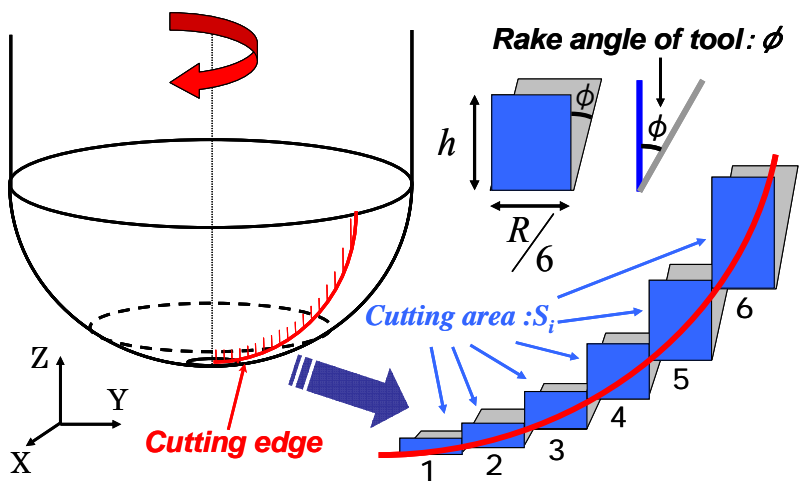

Fig.3 Definition of cutting area in ball end milling

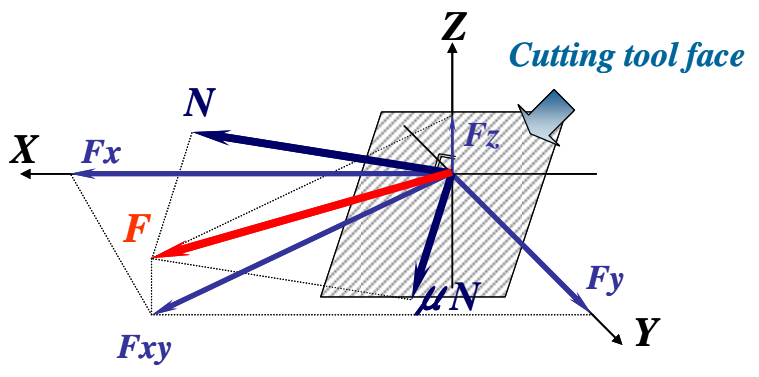

Fig.4 Dynamic relation on cutting tool face

interference part between the cutting tool and workpiece in six planes, as shown in Fig.3.

Equations 1 and 2 express the method of calculating the cutting force "F" from the cutting area. The vertical cutting force on the cutting tool face "N" (shown in Fig.4) is calculated by multiplying the cutting area " $\mathrm{S}$ " and specific cutting force "Ks". The cutting force " $F$ " is the result of multiplying the vertical cutting force " $\mathrm{N}$ " and the frictional force " $\mu \mathrm{N}$ " on the cutting tool face. The specific cutting force "Ks" is the parameter determined by combining the cutting tool and workpiece, which are obtained from basic cutting experiments. ${ }^{[2][3][4]}$

$$
\begin{aligned}
& N=K S \times S \\
& F=N+\mu N
\end{aligned}
$$

\subsection{Cutting Power Calculation Method}

To calculate the cutting energy "E (J)", the cutting power "Pc $(\mathrm{J} / \mathrm{s})$ " must be calculated. The cutting power shows the cutting energy in unit time, which means that the time integration of the cutting power is the cutting energy.

The following describes the method of calculating the cutting power in square end milling. In this study, the cutting power is calculated using the torque. To calculate this torque, cutting force " $\mathrm{F}_{\mathrm{T}}$ " is used. As a result, the cutting power is calculated from both the cutting force required for calculating the torque " $\mathrm{F}_{\mathrm{T}}$ " and the cutting speed "V ( $\mathrm{m} / \mathrm{min})$ " as shown in Equation (3). The cutting force required for calculating the torque " $\mathrm{F}_{\mathrm{T}}$ " is calculated using the vertical cutting force " $\mathrm{N}$ ", rake angle of the cutting tool " $\varphi$ ", and coefficient of friction " $\mu$ " as shown in Equation (4). Fig.5 show the square end milling is shown in this figure. The cutting power is calculated on the module for each specified tool rotation angle. 




Fig.5 Definition of " $F_{\mathrm{T}}$ " (Square end milling)

$$
\begin{aligned}
& P c=F_{T} \times V / 60 \\
& F_{T}=(\cos \varphi+\mu \sin \varphi) N
\end{aligned}
$$

The following describes the method of calculating the cutting power in ball end milling. The vertical cutting force " $\mathrm{N}$ " is calculated for each cutting area approximated in six planes. Using Equations (3) and (4), the cutting power is calculated for each cutting area, after which, the total cutting power for the ball end milling is calculated by summing up the cutting powers of the six cutting areas (Fig.6). Like for square end milling, the cutting power in ball end milling is calculated on the module for each specified tool rotation angle. ${ }^{[5]}$

\subsection{Cutting Energy Calculation Method}

Finally, the cutting energy is calculated. In both square end milling and ball end milling, the cutting energy is calculated on the module for each specified tool rotation angle, after which the total cutting energy "Total_E" is calculated by summing up all the cutting energies.

For example, when the tool rotation angle is specified as five degrees, the time taken for rotating five degrees " $t$ (s)" can be obtained as shown in Equation (5) from the cutting tool rotating speed. The cutting energy required for each specified tool rotation angle is calculated by using Equation (6), and the total cutting energy consumed in the cutting process "Total_E" can then be calculated by summing up the cutting energy consumed along the cutter path. ${ }^{[6]}$

$$
\begin{aligned}
& t=60 / n \times 5 / 360 \\
& E=P c \times t
\end{aligned}
$$

\section{Calculation of Energy Consumed by Each Unit of Machine Tool}

The average energy of peripheral equipment can be calculated through electric power measurement experiments of the energy consumed by each unit of the machine tool, for example, the average energy consumed in the feed drive motor in the $\mathrm{X}, \mathrm{Y}$ and $\mathrm{Z}$ directions, that consumed in the cooling system of the spindle, etc.. The machine tool was an actual machine tool; V33 from MAKINO MILLING MACHINE CO., LTD (Japan, Tokyo). (Fig.7)

The results of this experiment are summarized in Table.1.

The energy consumed in each unit of the machine tool in the cutting process "ME" is calculated by using these results. Equation (7) shows the method of calculating this energy using both the energy consumed by each unit of



Fig.6 Cutting power "Pc" in ball end milling

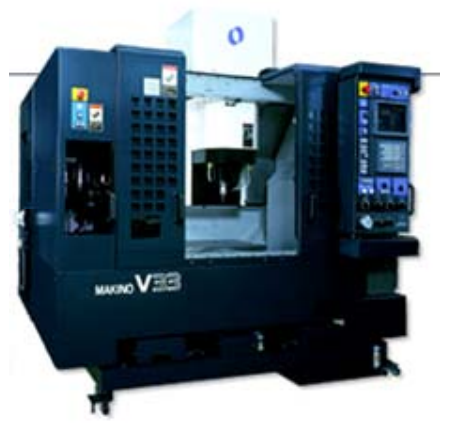

Fig.7 V33 from MAKINO MILLING MACHINE CO., LTD (Japan, Tokyo)

the machine tool in unit time and the time taken for the cutting tool to rotate at the specified tool rotation angle " $\Delta \mathrm{t} "$.

$$
\begin{aligned}
& M E=(\text { energy consumed by each unit } \\
& \text { of the machine tool in unit time }) \times \Delta t \quad(7)
\end{aligned}
$$

The energy consumed by all units of the machine tool "Total_ME" is calculated by summing up this energy "ME".

\section{Summary of Developed System}

The following describes the module for calculating the energy consumed by the machine tool developed in this study.

First, the input parameters are determined in the configuration file. Using the input parameters, the NC program, cutting tool data, workpiece data, machine tool data, and output format are determined. After determining the input parameters in the configuration file, the module for calculating the energy consumed in machine tool is run by reading the file.

As the output method, text data is output. The output items in the text data are determined by the output format in the configuration file. Seven output formats are prepared, for example, format of outputting cutting energy "E", energy consumed by each unit of the machine tool "ME", total cutting energy "Total_ E", energy consumed by all units of the machine tool "Total ME" and total energy consumed in the machine tool "All_Energy".

Using this module, the total cutting energy, energy consumed by all units of the machine tool, and total energy consumed in the machine tool can be confirmed.

One clear result obtained using this module was that in all cutting processes, the amount of energy consumed 
Table 1: Energy consumed by

each unit of machine tool

\begin{tabular}{|l|l|c|}
\hline \multicolumn{2}{|c|}{ Unit Name } & Power Consumption [W] \\
\hline \multirow{4}{*}{ Spindle Motor } & $5000[\mathrm{rpm}]$ & 250.0 \\
\cline { 2 - 3 } & $10000[\mathrm{rpm}]$ & 750.0 \\
\cline { 2 - 3 } & $15000[\mathrm{rpm}]$ & 1350.0 \\
\cline { 2 - 3 } & $20000[\mathrm{rpm}]$ & 2150.0 \\
\cline { 2 - 3 } & $25000[\mathrm{rpm}]$ & 3100.0 \\
\cline { 2 - 3 } & $30000[\mathrm{rpm}]$ & 4500.0 \\
\hline \multirow{4}{*}{ Feed Drive Motor } & $200[\mathrm{~mm} / \mathrm{min}]$ & 20.0 \\
\cline { 2 - 3 } & $1000[\mathrm{~mm} / \mathrm{min}]$ & 100.0 \\
\cline { 2 - 3 } & $2000[\mathrm{~mm} / \mathrm{min}]$ & 200.0 \\
\cline { 2 - 3 } & $5000[\mathrm{~mm} / \mathrm{min}]$ & 500.0 \\
\hline Cooling System of Spindle & 2050.0 \\
\hline Nozzle Coolant & 438.0 \\
\hline Coolant Temp, Controller & 363.0 \\
\hline Coolant Temp, Controller Suction Pump & 352.0 \\
\hline Oil Skimmer & 14.0 \\
\hline Lubrication Pump & 108.0 \\
\hline Chip Conveyor & 444.0 \\
\hline Mist Collector & 468.0 \\
\hline Air Dryer & 324.0 \\
\hline ATC & 72.0 \\
\hline
\end{tabular}

by each unit of the machine tool was more than the amount of cutting energy in the breakdown of the total energy consumed in the machine tool. In order to realize the purpose of this study, which is determining the machining conditions for minimizing the energy consumed by each unit of the machine tool, there is a need to find a machining method to minimize (save) energy consumed by the machine tool. It was verified that this requires the machining time to be as short as possible.

\section{Conclusion}

First, the cutting force occurring on the cutting tool face of end milling was calculated from the processing simulator. Using the torque of the cutting force, the cutting power and cutting energy were calculated. Next, the energy consumed by each unit of the machine tool was estimated by experiments using an actual machine tool. A module which can calculate the total energy consumed in the machine tool by summing up the cutting energy and the energy consumed by each unit was then developed. In addition, a basic system to determine the optimum machining conditions for minimizing energy consumed in the machine tool was proposed.
In the breakdown of the total energy consumed in the machine tool, the amount of energy consumed by each unit of the machine tool was more than the cutting energy amount. This confirmed that the machining time must be as short as possible in order to minimize the energy consumed in the machine tool.

\section{Future Work}

In the future, investigations on how the machine characteristics differing in each machine tool affect the energy consumed in the machine tool are required. These machine characteristics include spindle characteristics, feed drive motor characteristics, etc. In addition, how the machine characteristics affect the machining method to shorten the machining time must also be studied.

Furthermore, the module developed in this study must be applied to various types of machine tools in experiments so that it can be put to practical application. Finally, an easy-to-use interface must be developed.

\section{References}

[1]Yun.Won-Soo, Ko.Jeong Hoon, Lee.Han U1, Cho.Dong-Woo, and Ehmann.Kornel F, 2002, Development of a virtual machining system, part3: cutting process simulation in transient cuts, International Journal of Machine Tools \& Manufacture, Vol.42, No.15, pp.1617-1626.

[2]Bissey.S, Poulachon. G, and Lapujoulade. F, 2005, Modeling of tool geometry in prediction of cutting forces during milling of hard materials, Machining Science \& Technology, Vol.9, Vol.1, pp.101-115.

[3]Ko.Jeong Hoon, Yun.Won-Soo, Cho.Dong-Woo, and Ehmann.Kornel F, 2002, Development of a virtual machining system, part1: approximation of the size effect for cutting force prediction, International Journal of Machine Tools \& Manufacture, Vol.42, No.15, pp.1595-1605.

[4]Cherif.Mehdi, Thomas.Herve, Furet.Benoit, Hascoet.Jean-Yves, 2004, Generic modeling of milling forces for $\mathrm{CAD} / \mathrm{CAM}$ applications, International Journal of Machine Tools \& Manufacture, Vol.44, No.1, pp.29-37.

[5]Shao.H, Wang.H.L, and Zhao.X.M, 2004, A cutting power model for tool wear monitoring in milling, International Journal of Machine Tools \& Manufacture, Vol.44, Vol.14, pp.1503-1509.

[6]Polini.W, and Turchetta.S, 2004, Force and specific energy in stone cutting by diamond mill, International Journal of Machine Tools \& Manufacture, Vol.44, No.11, pp.1189-1196. 